Огляди літератури, оригінальні дослідження, погляд на проблему, ювілеї

удК 616-006-053.2-06:616.8]-07-085:615.847.8

DOI 10.11603/1811-2471.2018.v0.i2.8927

\title{
ДИНАМІКА КЛІНІЧНИХ ТА КЛІНІКО-ІНСТРУМЕНТАЛЬНИХ ПОКАЗНИКІВ У ДІТЕЙ З СУПУТНІМИ ЗАХВОРЮВАННЯМИ НЕРВОВОЇ СИСТЕМИ В ПЕРІОДІ РЕМІСІЇ ОНКОЗАХВОРЮВАНЬ ІЗ ДОДАТКОВИМ ПРИЗНАЧЕННЯМ МАГНІТОТЕРАПІЇ
}

\author{
๑Г. А. Шаповалова, К. Д. Бабов \\ ДУ «Український науково-дослідний інститут медичної реабілітації та курортології моз України», \\ м. Oдеса
}

РЕЗЮМЕ. Позитивний вплив магнітного поля при різних патологіях свідчить про доцільність вивчення ефективності магнітотерапії у комплексі санаторно-курортної реабілітації (СКР) дітей з супутніми захворюваннями нервової системи в періоді ремісії онкозахворювань (ОЗ).

Мета роботи - вивчення динаміки клінічних та клініко-інструментальних показників у дітей з супутніми захворюваннями нервової системи в періоді ремісії онкозахворювань із додатковим призначенням магнітотерапії.

Матеріали та методи. Фрагмент алгоритму обстеження дітей з ОЗ на етапі СКР включав загальне клінічне обстеження та інструментальні дослідження: електроенцефалографія (ЕЕГ); ехоенцефалографія (ЕхоЕГ); ультразвукова доплерографія (УЗДГ).

Для 25 дітей з супутніми захворюваннями нервової системи в періоді ремісії онкогематологічних захворювань (17 осі6) та солідних пухлин (8 осі6) додатково до загального комплексу СКР призначали магнітотерапію на шийнокомірцеву зону: магнітна індукція 20-30 мТл, експозиція 10-15 хвилин, через добу, на курс 5 процедур.

Результати. Застосування лікувального комплексу СКР з додатковим призначенням магнітотерапії дозволяє вірогідно зменшити скарги дітей у періоді ремісії ОЗ із супутніми захворюваннями нервової системи. За показниками УЗДГ встановлено статистично вірогідні позитивні зміни мозкової гемодинаміки. Результати Уз ЕхоЕГ свідчать про покращання ліквородинаміки. За даними ЕЕГ встановлено позитивні зміни в стані електрогенезу головного мозку.

Висновки. Слід визнати доцільним продовження досліджень для обгрунтування ролі інших фізичних факторів у санаторно-курортній реабілітації дітей в періоді ремісії ОЗ із супутньою патологією нервової системи.

КЛючОВІ СлОВА: діти; онкологічні захворювання; санаторно-курортна реабілітація; магнітотерапія.

Вступ. Низькочастотна магнітотерапія - лікувальне застосування магнітної складової змінного електромагнітного поля низької частоти. Лікувальні ефекти низькочастотного магнітного поля: судинорозширювальний, катаболічний, протизапальний, ангіопротекторний, трофічний, гіпокоагулювальний, гіпотензивний [1].

Обгрунтувано застосування низькочастотного магнітного поля для збільшення швидкості проведення імпульсів по нервових волокнах, підвищення їх збудливості, зменшення периневрального набряку, підвищення збудливості ЦНС [2].

Вищезазначене свідчить про доцільність вивчення ефективності магнітотерапії у комплексі санаторно-курортної реабілітації (CKP) дітей з супутніми захворюваннями нервової системи в періоді ремісії онкозахворювань.

Мета роботи - вивчення динаміки клінічних та клініко-інструментальних показників у дітей 3 супутніми захворюваннями нервової системи в періоді ремісії онкозахворювань із додатковим призначення магнітотерапії.

Матеріал і методи дослідження. Фрагмент алгоритму обстеження дітей з О3 на етапі СКР включав загальне клінічне обстеження та інструментальні дослідження: електроенцефалографія (ЕЕГ); ехоенцефалографія (ЕхоЕГ); ультразвукова доплерографія (УзДг) [3].
Додатково до загального комплексу СКР [4] для 25 дітей з супутніми захворюваннями нервової системи в періоді ремісії онкогематологічних захворювань (17 осіб) та солідних пухлин (8 осіб) додатково призначали магнітотерапію на шийно-комірцеву зону: магнітна індукція 20-30 мТл, експозиція 10-15 хвилин, через добу, на курс 5 процедур.

Результати й обговорення. Як показано у таблиці 1, додаткове призначення магнітотерапії дозволяє вірогідно зменшити майже всі скарги дітей.

За показниками УзДГ (табл. 2) встановлено статистично вірогідні позитивні зміни мозкової гемодинаміки: зменшення церебральної ангіодистонії, асиметрії кровообігу та венозної дисгемії, підвищення резерву кровообігу та покращання адаптаційних можливостей апарату ауторегуляції мозкового кровообігу.

За показниками УЗ ЕХоЕГ (табл. 3) виявлено покращання ліквородинаміки у вигляді статистично вірогідного зменшення явищ внутрішньочерепної гіпертензії та частоти реєстрації додаткових Ехо-сигналів, зменшення удвічі проявів гіпертензійно-лікворного синдрому та утричі - індексу пульсації.

За показниками ЕЕГ (табл. 4) встановлено позитивні зміни в стані електрогенезу головного мозку із нормалізацією біоелектричної активності та статистично вірогідним покращанням функціональної активності кори. 
Огляди літератури, оригінальні дослідження, погляд на проблему, ювілеї

Таблиця 1. Динаміка скарг у дітей з ОЗ із супутніми захворюваннями нервової системи після комплексу

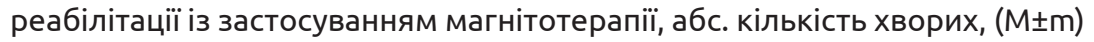

\begin{tabular}{|c|c|c|c|c|}
\hline \multirow[t]{2}{*}{ Скарги } & \multicolumn{2}{|c|}{$\begin{array}{c}\text { Лікувальний комплекс із } \\
\text { магнітотерапією } \\
\mathrm{n}=25\end{array}$} & \multicolumn{2}{|c|}{$\begin{array}{c}\text { Загальний комплекс } \\
\text { n= } 30\end{array}$} \\
\hline & до СКР & після СКР & до СКР & після СКР \\
\hline Слабкість, швидка стомлюваність & $22(88,0 \pm 6,5)$ & $6(24,0 \pm 8,5)^{*}$ & $26(86,7 \pm 6,2)$ & $18(60,0 \pm 9,0) * a$ \\
\hline Тривожність & $10(40,0 \pm 9,8)$ & $2(8,0 \pm 5,4) *$ & $12(40,0 \pm 8,9)$ & $6(20,0 \pm 7,3)$ \\
\hline Лабільність настрою, пригніченість & $11(44,0 \pm 9,9)$ & $4(16,0 \pm 7,3)^{*}$ & $6(20,0 \pm 7,3)$ & $4(13,3 \pm 6,2)$ \\
\hline Поганий апетит & $7(28,0 \pm 9,0)$ & $3(12,0 \pm 6,5)$ & $8(26,7 \pm 8,0)$ & $6(20,0 \pm 7,3)$ \\
\hline Дратівливість & $15(60,0 \pm 9,8)$ & $5(20,0 \pm 8,0) *$ & $18(60,0 \pm 8,9)$ & $10(33,3 \pm 8,6)^{*}$ \\
\hline Порушення сну & $8(32,0 \pm 9,3)$ & $1(4,0 \pm 3,9) *$ & $10(33,3 \pm 8,6)$ & $6(20,0 \pm 7,3)$ \\
\hline Порушення уваги & $15(60,0 \pm 9,8)$ & $6(24,0 \pm 8,5) *$ & $18(60,0 \pm 8,9)$ & $10(33,3 \pm 8,6)^{*}$ \\
\hline Головні болі & $18(72,0 \pm 9,0)$ & $8(32,0 \pm 9,3) *$ & $21(70,0 \pm 8,4)$ & $15(50,0 \pm 9,1)$ \\
\hline $\begin{array}{l}\text { Запаморочення, нестерпність } \\
\text { транспорту, духоти }\end{array}$ & $19(76,0 \pm 8,5$ & $6(24,0 \pm 8,5) *$ & $22(73,3 \pm 8,0)$ & $18(60,0 \pm 8,9) a$ \\
\hline Відчуття «грудки» в горлі & $12(48,0 \pm 9,9)$ & $2(8,0 \pm 5,4) *$ & $14(46,7 \pm 9,1)$ & $8(26,7 \pm 8,1)$ \\
\hline Холодні та вологі долоні & $7(28,0 \pm 9,0)$ & $2(8,0 \pm 5,4)$ & $8(26,7 \pm 8,1)$ & $6(20,0 \pm 7,3)$ \\
\hline Короткочасні болі у ділянці серця & $10(40,0 \pm 9,8)$ & $4(16,0 \pm 7,3)$ & $12(40,0 \pm 8,9)$ & $8(26,7 \pm 8,1)$ \\
\hline Тахікардія & $5(20,0 \pm 8,0)$ & $2(8,0 \pm 5,4)$ & $6(20,0 \pm 7,3)$ & $6(20,0 \pm 7,3)$ \\
\hline
\end{tabular}

Примітка. * - p<0,05 - вірогідність різниці між показниками до та після лікування; $a$ - р<0,05-вірогідність різниці між досягнутими показниками комплексів після лікування.

Таблиця 2. Динаміка показників УзДг магістральних судин голови та шиї у дітей з ОЗ із супутніми захворюваннями нервової системи після комплексу реабілітації із застосуванням магнітотерапії, абс. кількість хворих, $\mathrm{M} \pm \mathrm{m}$

\begin{tabular}{|c|c|c|c|c|}
\hline \multirow[t]{2}{*}{ Показники } & \multicolumn{2}{|c|}{$\begin{array}{c}\text { Лікувальний комплекс із } \\
\text { магнітотерапією } \\
\text { n=25 }\end{array}$} & \multicolumn{2}{|c|}{$\begin{array}{c}\text { Загальний комплекс } \\
\text { n=30 }\end{array}$} \\
\hline & до СКР & після СКР & до СКР & після СКР \\
\hline Церебральна ангіодистонія & $17(68,0 \pm 9,3)$ & $10(40,0 \pm 9,8)^{*}$ & $21(70,0 \pm 8,4)$ & $15(50,0 \pm 9,1)$ \\
\hline Зниження резерву кровообігу & $20(80,0 \pm 8,0)$ & $10(40,0 \pm 9,8)^{*}$ & $24(80,0 \pm 7,3)$ & $20(66,7 \pm 8,6)$ \\
\hline Асиметрія кровообігу & $18(72,0 \pm 9,0)$ & $10(40,0 \pm 9,8)^{*}$ & $22(73,3 \pm 8,1)$ & $18(60,0 \pm 8,9)$ \\
\hline $\begin{array}{l}\text { Зниження адаптаційної здатності } \\
\text { апарату ауторегуляції }\end{array}$ & $15(60,0 \pm 9,8)$ & $8(32,0 \pm 9,3) *$ & $18(60,0 \pm 8,9)$ & $14(46,7 \pm 9,1)$ \\
\hline Венозна дисгемія, & $22(88,0 \pm 6,5)$ & $12(48,0 \pm 9,9)^{*}$ & $27(90,0 \pm 5,5)$ & $20(66,7 \pm 8,6) *$ \\
\hline
\end{tabular}

Примітка. * - p<0,05 - вірогідність різниці між показниками до та після лікування.

Таблиця 3. Динаміка показників УЗ ЕхоЕГ у дітей з ОЗ із супутніми захворюваннями нервової системи після

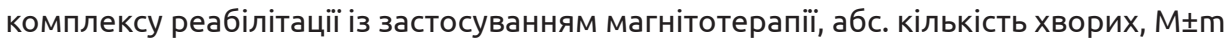

\begin{tabular}{|c|c|c|c|c|}
\hline \multirow[t]{2}{*}{ Показники } & \multicolumn{2}{|c|}{$\begin{array}{c}\text { Лікувальний комплекс із } \\
\text { магнітотерапією } \\
\text { n= } 25\end{array}$} & \multicolumn{2}{|c|}{$\begin{array}{l}\text { Загальний комплекс } \\
\text { n= } 30\end{array}$} \\
\hline & до СКР & після СКР & до СКР & після СКР \\
\hline $\begin{array}{l}\text { Явища внутрішньочерепної } \\
\text { гіпертензії, \% }\end{array}$ & $22(88,0 \pm 6,5)$ & $10(40,0 \pm 9,8)^{*}$ & $27(90,0 \pm 5,5)$ & $20(66,7 \pm 8,6) *_{a}$ \\
\hline $\begin{array}{l}\text { Гіпертензійно-лікворний } \\
\text { синдром, \% }\end{array}$ & $10(40,0 \pm 9,8)$ & $5(20,0 \pm 8,0)$ & $12(40,0 \pm 8,9)$ & $10(33,3 \pm 8,6)$ \\
\hline $\begin{array}{l}\text { Підвищення індексу } \\
\text { пульсацій, \% }\end{array}$ & $6(24,0 \pm 8,5)$ & $2(8,0 \pm 5,4)$ & $7(23,3 \pm 7,7)$ & $4(13,3 \pm 6,2)$ \\
\hline Додаткові Ехо-сигнали, \% & $8(32,0 \pm 9,3)$ & $2(8,0 \pm 5,4) *$ & $10(33,3 \pm 8,6)$ & $10(33,3 \pm 8,6) \mathfrak{a}$ \\
\hline
\end{tabular}

Примітка. * - p<0,05 - вірогідність різниці між показниками до та після лікування; $а$ - р<0,05 - вірогідність різниці між досягнутими показниками комплексів після лікування. 
Огляди літератури, оригінальні дослідження, поглядна проблему, ювілеї

Таблиця 4. Динаміка показників ЕЕГ у дітей з ОЗ із супутніми захворюваннями нервової системи після комплексу

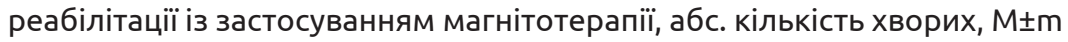

\begin{tabular}{|l|c|c|c|c|}
\hline \multirow{2}{*}{\multicolumn{1}{|c|}{ Показники }} & \multicolumn{2}{|c|}{$\begin{array}{c}\text { Лікувальний комплекс із } \\
\text { магнітотерапією } \mathrm{n}=25\end{array}$} & \multicolumn{2}{c|}{$\begin{array}{c}\text { Загальний комплекс } \\
\mathrm{n}=30\end{array}$} \\
\cline { 2 - 5 } & до СКР & після СКР & до СКР & після СКР \\
\hline Зміни електрогенезу, \% & $15(60,0 \pm 9,8)$ & $8(32,0 \pm 9,3)^{*}$ & $18(60,0 \pm 8,9)$ & $16(53,3 \pm 9,1)$ \\
\hline $\begin{array}{l}\text { Зміни функціональної } \\
\text { активності, \% }\end{array}$ & $15(60,0 \pm 9,8)$ & $7(28,0 \pm 9,0)^{*}$ & $18(60,0 \pm 8,9)$ & $14(46,7 \pm 9,1) \mathfrak{a}$ \\
\hline
\end{tabular}

Примітка. * - p<0,05-вірогідність різниці між показниками до та після лікування; $a-$ р<0,05 - вірогідність різниці між досягнутими показниками комплексів після лікування

У монографії [4] $\epsilon$ посилання на роботи щодо застосування магнітного поля з метою зменшення побічних впливів променевої і хіміотерапії пухлин; протекторної дії магнітної індукції до 30 мТл від радіації; використання магнітного поля для стимуляції імунних реакцій в онкологічних хворих. У роботі [5] обгрунтована ефективність штучних магнітних полів в реабілітації дітей зі злоякісними пухлинами.

Висновки. 1. Застосування лікувального комплексу СКР з додатковим призначенням магнітотерапії дозволяє вірогідно зменшити скарги дітей у періоді ремісії О3 із супутніми захворюваннями нервової системи.

2. За показниками УЗДГ встановлено статистично вірогідні позитивні зміни мозкової гемодинаміки. Результати УЗ ЕхоЕГ свідчать про покращання ліквородинаміки. За даними ЕЕГ встановлено позитивні зміни в стані електрогенезу головного мозку.

3. Слід визнати за доцільне продовження досліджень для обгрунтування ролі інших фізичних факторів у санаторно-курортній реабілітації дітей в періоді ремісії ОЗ із супутньою патологією нервової системи.

\section{ЛІТЕРАТУРА}

1. Ушаков А. А. Практическая физиотерапия. - 2-е изд., испр. и доп. - М. : ООО «Медицинское информационное агентство", 2009. - 608 с.

2. Ежов В. В. Физиотерапия для врачей общей практики. Руководство для врачей / В. В. Ежов, Ю. И. Андрияшек. - Симферополь-Ялта, 2005. - 400 с.

3. Нейрофизиологические исследования в клинике / ред. Г. А. Щекутьев. - М. : Антидор, 2011. - 232 с.

4. Реабілітація дітей із онкогематологічними захворюваннями в санаторно-курортних умовах : по-

\section{REFERENCES}

1. Ushakov, A.A. (2009). Prakticheskaya fizioterapiya (2-ye izd., ispr. i dop.) [Practical physiotherapy (2nd ed., rev. and add.)]. Moscow: Medical Information Agency LLC [in Russian].

2. Yezhov, V.V. \& Andriyashek, Yu.I. (2005). Fizioterapiya dlya vrachey obshchey praktiki. Rukovodstvo dlya vrachey [Physiotherapy for general practitioners. Manual for doctors]. Simferopol-Yalta [in Russian].

3. Shchekutev, G.A. (Ed.) (2011). Neyrofiziologicheskiye issledovaniya v klinike [Neurophysiological studies in clinic]. Moscow: "ANTIDOR" [in Russian].

4. Babov, K.D. \& Poberska, V.O. (Ed.) (2010). Reabilitatsiia ditei iz onkohematolohichnymy zakhvoriuvanniamy $v$

сібник / за ред. К. Д. Бабова, В. О. Поберської. - Одеса: Optimum, 2010. - 160 c.

5. Грушина Т. И. Реабилитация в онкологии: физиотерапия / Т. И. Грушина. - М. : ГЭОТАР - Медиа, 2006. 240 c.

6. Киселев А. В. Использование искусственных магнитных полей в реабилитации детей со злокачественными опухолями / А. В. Киселев, Т. И. Грушина // Вопросы онкологии. - 2000. - Т. 46, № 4. - С. 469-472.

sanatorno-kurortnykh umovakh. Posibnyk [Rehabilitation of children with oncohematological diseases at the conditions of sanatorium-and-resort. Manual]. Odesa: Optimum [in Ukrainian].

5. Grushina, T.I. (2006). Reabilitatsiia v onkolohii: fizioterapiia [Rehabilitation in oncology: physiotherapy]. Moscow: GEOTAR-Media [in Russian].

6. Kiselev, A.V. \& Grushina, T.I. (2000). Ispolzovaniye iskusstvennykh magnitnykh poley $v$ reabilitatsii detey so zlokachestvennymi opukholyami [Use of artificial magnetic fields in the rehabilitation of children with malignant tumors]. Voprosy onkologii - Questions of Oncology, 46, 4, 469-472 [in Russian]. 


\section{ДИНАМИКА КЛИНИЧЕСКИХ И КЛИНИКО-ИНСТРУМЕНТАЛЬНЫХ ПОКАЗАТЕЛЕЙ У ДЕТЕЙ С СОПУТСТВУЮЩИМИ ЗАБОЛЕВАНИЯМИ НЕРВНОЙ СИСТЕМЫ В ПЕРИОДЕ РЕМИССИИ ОНКОЗАБОЛЕВАНИЙ С ДОПОЛНИТЕЛЬНЫМ НАЗНАЧЕНИЕМ МАГНИТОТЕРАПИИ}

๑А. А. Шаповалова, К. Д. Бабов

ГУ «Украинский научно-исследовательский институт медицинской реабилитации и курортологии МЗ Украины", г. Одесса

РЕЗЮМЕ. Положительное влияние магнитного поля при различных патологиях свидетельствует о целесообразности изучения эффективности магнитотерапии в комплексе санаторно-курортной реабилитации (СКР) детей с сопутствующими заболеваниями нервной системы в периоде ремиссии онкозаболеваний (О3).

Цель работы - изучение динамики клинических и клинико-инструментальных показателей у детей с сопутствующими заболеваниями нервной системы в периоде ремиссии онкозаболеваний с дополнительным назначением магнитотерапии.

Материалы и методы. Фрагмент алгоритма обследования детей с ОЗ на этапе СКР включал общее клиническое обследование и инструментальные исследования: электроэнцефалографию (ЭЭГ); эхоэнцефалографию (ЭхоЭГ); ультразвуковую допплерографию (УЗДГ).

Для 25 детей с сопутствующими заболеваниями нервной системы в периоде ремиссии онкогематологических заболеваний (17 детей) и солидных опухолей (8 детей) дополнительно к общему комплексу СКР назначали магнитотерапию на шейно-воротниковую зону: магнитная индукция 20-30 мТл, экспозиция 10-15 минут, через сутки, на курс 5 процедур.

Результаты. Применение лечебного комплекса СКР с дополнительным назначением магнитотерапии позволяет достоверно уменьшить жалобы детей в периоде ремиссии ОЗ с сопутствующими заболеваниями нервной системы. По показателям УЗДГ установлено статистически достоверные положительные изменения мозговой гемодинамики. Результаты ЭхоЭГ свидетельствуют об улучшении ликвородинамики. По данным ЭЭГ установлены положительные изменения в состоянии электрогенеза головного мозга.

Выводы. Следует признать целесообразным продолжение исследований относительно обоснования роли других физических факторов в санаторно-курортной реабилитации детей в периоде ремиссии ОЗ с сопутствующей патологией нервной системы.

КЛюЧЕВЫЕ СЛОВА: дети; онкологические заболевания; санаторно-курортная реабилитация; магнитотерапия.

\section{DYNAMICS OF CLINICAL AND CLINICAL-INSTRUMENTAL INDICES IN CHILDREN WITH ACCOMPANYING DISEASES OF THE NERVOUS SYSTEM IN THE PERIOD OF REMISSION OF CANCER WITH ADDITIONAL ADMINISTRATION OF MAGNETOTHERAPY}

@A. A. Shapovalova, K. D. Babov

Ukrainian Research Institute of Medical Rehabilitation and Balneology of the Ministry of Health of Ukraine

SUMMARY. The positive effect of the magnetic field under various pathological conditions indicates the advisability of studying magnetotherapy's effectiveness in a complex of sanatorium-resort rehabilitation (SRR) of children with concomitant diseases of the nervous system in the period of remission of oncological diseases (OD).

The aim: to study the dynamics of clinical and clinical-instrumental indicators in children with concomitant diseases of the nervous system in the period of remission of oncological diseases with the additional use of magnetotherapy.

Material and Methods. The fragment of the algorithm for examining children with OD at SRR included a general clinical examination and instrumental researches: electroencephalography (EEG); echoencephalography (EchoEG); ultrasound dopplerography (UZDG).

For 25 children with concomitant diseases of the nervous system, in the period of remission of oncohematological diseases (17 persons) and solid tumors (8 persons), in addition to the general complex of SCR, magnetotherapy was administered to the cervical collar zone: magnetic induction 20-30 mTl, 15 minutes, in a day, 5 procedures per course.

Results. The use of the medical complex of SRR with the additional administartion of magnetotherapy can reliably reduce the complaints of children in the period of remission of OD with concomitant diseases of the nervous system. Statistically significant positive changes in cerebral hemodynamics were established by USDG indicators. The results of EchoEG testify to the improvement of liquorodynamics. According to the EEG, positive changes in the state of brain electrogenesis have been established.

The conclusion. It should be considered appropriate to continue research on the rationale for the role of other physical factors in the sanatorium rehabilitation of children in the period of remission of OD with concomitant pathology of the nervous system.

KEY WORDS: children; oncological diseases; sanatorium rehabilitation; magnetotherapy. 